\title{
5-(N-methylmaleimid-3-yl)-chromone, a novel microtubule inhibitor, exerts anti-proliferative effects in MDR cancer cells and cancer stem cells
}

\author{
Mina Park ${ }^{1}$, Jee Won Hwang ${ }^{1}$, Yena Cho ${ }^{1}$, Saegun Kim² ${ }^{2}$ Sang Hoon Han ${ }^{2}$, Jinsuh Yu \\ Woo-Young Kim ${ }^{1}$, Su-Nam Kim ${ }^{3}$, In $\mathrm{Su} \mathrm{Kim}^{2}$, and Yong Kee Kim${ }^{1}$ \\ ${ }^{1}$ Sookmyung Women's University \\ ${ }^{2}$ Sungkyunkwan University \\ ${ }^{3}$ Korea Institute of Science and Technology
}

September 11, 2020

\begin{abstract}
Background and Purpose: The success of cancer chemotherapy is limited by multidrug resistance (MDR), which is mainly caused by P-glycoprotein (P-gp) overexpression. In the present study, we describe a novel microtubule inhibitor, 5-(N-methylmaleimid3-yl)-chromone (SPC-160002), that can be used to overcome MDR. Experimental Approach: Key Results: A synthetic chromone derivative, SPC-160002, showed a broad spectrum of anti-proliferative effects on various human cancer cells without affecting P-gp expression and its drug efflux function. Treatment with SPC-160002 arrested the cell cycle at the M phase, as evidenced using fluorescence-activated cell sorting analysis, and increased the levels of mitotic marker proteins, including cyclin B, pS10H3, and chromosomal passenger complex. This mitotic arrest by SPC-160002 was mediated by promoting and stabilizing microtubule polymerization, similar to the mechanism observed in case of taxane-based drugs. Furthermore, SPC-160002 suppressed the growth and sphere-forming activity of cancer stem cells. Conclusion and Implications: Our data herein strongly suggest that SPC-160002, a novel microtubule inhibitor, can be used to overcome MDR and can serve as an attractive candidate for anticancer drugs.
\end{abstract}

\section{Hosted file}

SPC-160002_BJP-MS.docx available at https://authorea.com/users/357484/articles/480596-5-nmethylmaleimid-3-yl-chromone-a-novel-microtubule-inhibitor-exerts-anti-proliferativeeffects-in-mdr-cancer-cells-and-cancer-stem-cells 
figures/Fig-1-BJP/Fig-1-BJP-eps-converted-to.pdf

\section{Hosted file}

Fig 2-BJP.eps available at https://authorea.com/users/357484/articles/480596-5-nmethylmaleimid-3-yl-chromone-a-novel-microtubule-inhibitor-exerts-anti-proliferativeeffects-in-mdr-cancer-cells-and-cancer-stem-cells 
figures/Fig-3-BJP/Fig-3-BJP-eps-converted-to.pdf 
figures/Fig-4-BJP/Fig-4-BJP-eps-converted-to.pdf

\section{Hosted file}

Fig 5-BJP.eps available at https://authorea.com/users/357484/articles/480596-5-nmethylmaleimid-3-yl-chromone-a-novel-microtubule-inhibitor-exerts-anti-proliferativeeffects-in-mdr-cancer-cells-and-cancer-stem-cells 
figures/Fig-6-BJP/Fig-6-BJP-eps-converted-to.pdf 